\title{
Effects of Rio de Janeiro Ar Livre program on the autonomy of octogenarian elderly women
}

\author{
Larissa Aguirres, Helio Furtado, Gabriela Rezende de Oliveira Venturini, Flavia Porto, José \\ Manuel Vilaça Maio-Alves, Nádia Souza Lima da Silva ${ }^{*}$
}

ORIGINAL ARTICLE

\begin{abstract}
With the increase in life expectancy, it is important to acknowledge the impact of health promotion programs on the elderly. The aimed of this study was to evaluate the influence of the Rio de Janeiro Ar Livre physical program on the functional autonomy of octogenarian elderly women's. To this end, elderly women's from 19 Rio de Janeiro Ar Livre program gyms were selected for the experimental group (EG) $(n=23 ; 82.57 \pm 3.78$ years $)$, and for the Control Group (CG) $(n=17 ; 82.88 \pm 2.23$ years $)$ from the attending cohabitation houses of the City of Rio de Janeiro. To access the functional autonomy was used Rikli and Jones (1999) protocol in two times separated by (28 weeks). It was observed in the EG a significant $(\mathrm{p}=0.010)$ increase in Upper limbs' strength test $(13.00 \pm 3.41$ to $15.09 \pm 3.60$ times, pre and post innervation, respectively) and a significant $(\mathrm{p}=0.002)$ increase in 2 minutes Step test in the CG $(36.59 \pm 15.00$ to $47.24 \pm 10.96$ times, pre and post, respectively). However, any significant differences between groups were observed in all variables analysed. Based in the present data we can conclude that the training program was only effective in the promotions of the functional strength of the upper limbs and to maintain the functional autonomy of octogenarian elderly women.

Keywords: elderly, public health, functional autonomy.
\end{abstract}

\section{INTRODUCTION}

The In Brazil, since the implantation of the Global health system (SUS), which offered free healthcare to every citizen, the concern about not-transmissible chronic diseases (DCNT) became clear, mainly because the natality index lowered while life expectancy (Ribeiro, 2014). With this issue in mind, one of the Health Ministry's actions was the creation of the National Policy of the Elderly Person (PNSPI), whose principles, among others, are active and healthy aging and full and integrated attention to the elderly person (Ministério da Saúde, 2006). Based on the PNSPI, other public policies have been created in order to attain health and quality of life in the elderly population, stimulating their autonomy (World Health Organization [WHO], 2015).

There are different definitions of functional autonomy. Nevertheless, it is frequently described as the ability to execute predetermined domestic tasks, or similar concepts, being strictly related to an individual's capacity to control its life. Therefore, it directly linked to quality of life
(Farinatti, Assis, \& Silva, 2008). Regular practice of physical exercises is way of reducing the detrimental effects of aging in the body, as well as frailty installation, positively influencing functional autonomy (Jankovic et al., 2015).

In the city of Rio de Janeiro, "Rio Ar Livre " (RAL) was created as a public policy to address this particular issue, by the Municipal Secretary of Healthy Aging, Resilience and Care (SEMEARC/RJ), mostly dedicated to the elderly population. RAL consists in the offer of physical exercises under orientation of Physical Education professionals, in gyms installed in public squares scattered around the city neighborhoods (Special Secretariat for Healthy aging and quality of life [SESQV], 2010). This facilitates both access and adhesion of the population regarding the regular practice of physical exercise. Rio de Janeiro, at the time of writing, had 143 of such units around the town (SESQV, 2010).

Due to its characteristics and objectives, RAL represents an important public policy. However, owning to the fact that the gyms are composed of adapted gym equipment, which can not be

Manuscript received at August $4^{\text {th }} 2018$; Accepted at December $12^{\text {th }} 2018$

* Corresponding author: nadiaslimas@gmail.com 
adjusted to control increment and training overload (Silva, Brasil, Furtado, Costa, \& Farinatti, 2014), there is still doubt about its impact, mainly around the maintenance or improvement in functional autonomy of the elderly who perform these activities. The doubt is even bigger when it is taken into account the attending public whose age is equal or greater than 80 years, a population that lacks studies in this type of program.

In the RAL the female public were presented in greater quantity. This preponderance of the female sex reflects what is observed in the global elderly population (Küchemann, 2012). Küchemann (2012) describes a feminization process upon aging, stating that as the older a population gets, the more feminine it becomes. Among the factors which influence this phenomenon, it is important to mention the greater continuous medical attention sought by women and less violent deaths, which affect young men in $90 \%$ of the cases (Bandeira, Melo, $\&$ Pinheiro, 2010).

If the Brazil the female elder population and life expectancy increase, it is important to know this particular public's needs and the impact of health promotion public policies towards it. So, the aim of the present study was to evaluate the effects of the training program performed in the RAL gyms on the functional autonomy of octogenarian elderly women.

\section{METHOD}

The present study is experimental, majorly of quantitative nature, inferential in depth (Appolinário, 2012).

\section{Participants}

The amount of participating RAL gyms was statistically determined, designed to cover all of the city regions, to adequately represent the city's situation. Gym selection was random, being selected, of the 143 existent when data collection was performed, 24 to be included in the study. However, only 22 of the 24 selected gyms had 80 years or older members of feminine sex, and of those only in 19 the subjects attended to both evaluations.
Subjects from each RAL included were sampled by probabilistic method, to ensure any individual could be part of the sample, thus assuring the investigated population's representativeness and the statistical test's potency (Thomas, Nelson, \& Silverman, 2012).

The inclusion in each of the experiment's groups was also randomly made among those who fulfilled the inclusion criteria. The experiment started with a total of 96 subjects, however, 56 did not attend on the agreed date, abandoned the project or preferred not to take part in the second evaluation. Therefore, the research was carried out with 40 subjects, which composed the Experimental Group (EG) and the Control Group (CG).

The experimental group (EG) was composed of 23 elderly women $(82.57 \pm 3.78$ years). The inclusion criteria of this group was as following: a) having age equal to or greater than 80 years; b) being registered in RAL; c) having no restriction to perform the tests utilized in the research; d) having signed the Informed Consent Terms, as determined by National Health Council Resolution 466/12 (Ministério da Saúde, 2012).

The CG was composed of 17 elderly $(82.88 \pm 2.23$ years), all who attended to Rio de Janeiro City Hall's cohabitation houses. The following criteria was adopted in this group: a) having age equal to or greater than 80 years; b) being enrolled in cohabitation houses; c) having no restrictions to perform the tests utilized in the research; d) having signed the Informed Consent Form.

Cohabitation houses were selected as the CG due to the ease of programming visits to perform the evaluations and attain a reasonable amount of subjects. Furthermore, it is also a governmental program with a similar public as the RAL. All of the six houses existent in Rio de Janeiro were evaluated (Penha, Tijuca, Gávea, Lagoa, São Conrado and Botafogo. Figure 1 illustrates volunteer allocation process.

The period of intervention in the EG was 28 weeks and the Functional tests were performed pre and post intervention in both groups.

The research project was previously approved by the Human Being Research Ethical Committee, part of the Rio de Janeiro's Municipal 
Health Secretary and Civil Defense (CAAE

Protocol: 22065913.5.0000.5279).

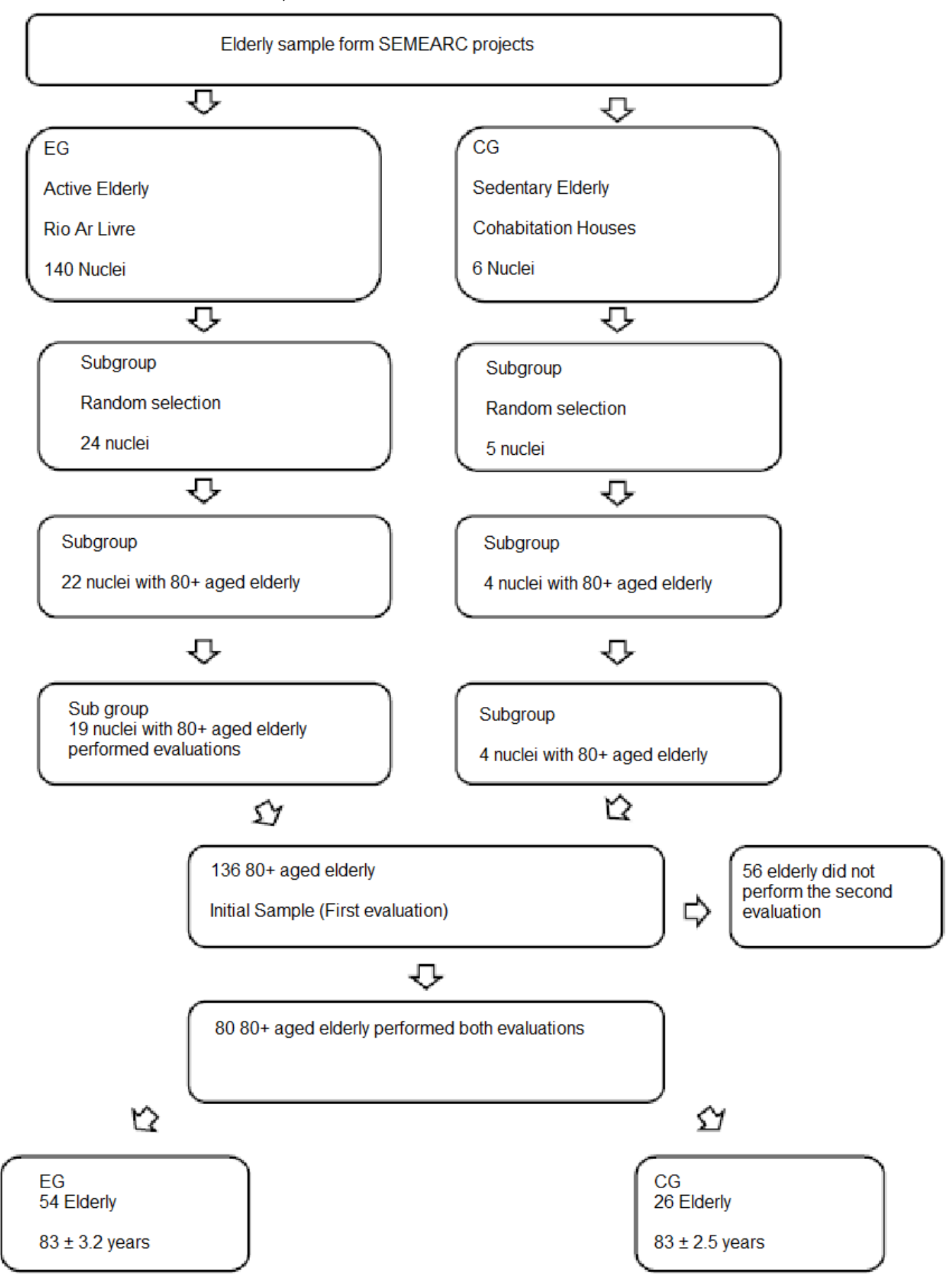

Figure 1. volunteer allocation process

\section{Measures and Procedures}

Competition Training protocol

The training protocol consisted in a mixed circuit, interspersing aerobic and muscular resistance exercises. The circuit utilized the walking and the ski stimulator; resisted exercises were performed in machines: seated leg press, vertical bench press, leg extension, shoulder press, leg flexion, lat pulldown and seated row. The circuit was divided into seven stations: 1st walking simulator; $2^{\text {nd }}-$ muscular resistance exercises; $3^{\text {rd }}-$ Ski stimulator; $4^{\text {th }}-$ muscular 
resistance exercises; $5^{\text {th }}$-walking stimulator; $6^{\text {th }}$ muscular resistance exercises; and $7^{\text {th }}-$ Ski stimulator. In the $1^{\text {st }}, 3^{\text {rd }}, 5^{\text {th }}$ and $7^{\text {th }}$ stations the aerobic exercises were performed for 5 minutes. In the $2^{\text {nd }}, 4^{\text {th }}$ and $6^{\text {th }}$ stations were performed one set of fifteen repetitions of each resistance exercises. The time rest between stations and resistance exercises sets was 20 seconds and all exercises used the body and machine weight as load.

\section{Anthropometric measuring}

Subject profiling was made according to the groups' Body Mass Index (BMI) and age. To determine the BMI, mass was measured with a Techline brand digital scale (São Paulo, Brazil), and height with a Sanny stadiometer (São Paulo, Brazil), using the standardization described by Gordon et al. (1988) and Martin et al. (1988), respectively. To calculate the BMI, subject mass in kilograms $(\mathrm{kg})$ was divided by its height squared, in meters $(\mathrm{m})$.

\section{Functional Autonomy Evaluation}

To evaluate functional autonomy, the Rikli and Jones $(1999,2002)$ test protocol was used, aiming to analyze fitness status associated to mobility and self-government in the program participants.

The Rikli and Jones (1999, 2002) protocol consists in easy-to-use battery of test items that assess the functional fitness of older adults. The test describes easy to understand and effective tests to measure aerobic fitness, muscular strength and range of movement capacity of upper and lower limbs, agility and dynamic balance (Rikli \& Jones, 1999, 2002), using minimal and inexpensive equipment enabling the testing to occur in the same public plazas where the program took place.

The tests were conduced in the morning by a properly certified and trained team to ensure reliability of the gathered data. The tests were divided in stations to speed the gathering process, each examiner being responsible for one station. In each station one subject was evaluated at a time, and a five-minute rest interval was given between the tests.
Stations were organized as follows: 1) measuring and weighing; 2) sitting and standing (SS), elbow flexion (EF), sit and reach test (SRT), back reach (BR) and Time Up and Go tests (TUG) ; 3) 2 minute Step test (2MST).

According to Rikli and Jones's Senior Fitness Test, tests were performed in the described manner:

\section{Sitting and Standing}

The subject started sitting in a chair without arm rests, with its back lying on the chair and feet completely bound to the ground. At the examiner's command, it was instructed to stand um and sit down again the maximum amount it could in $30 \mathrm{~s}$. Time was measured by a chronometer Vollo VL237 (São Paulo, Brazil).

\section{Elbow Flexion}

The subject started sitting in a chair without arm rests, with its back lying on the chair and feet completely bound to the ground. At the examiner's command, it was instructed to perform the maximum amount possible of elbow flexions in $30 \mathrm{~s}$. Flexion started in neutral position and ended in supine position. In this test a $2.27 \mathrm{~kg}$ dumbbell was used.

\section{Sit and reach}

The subject started sitting in a chair without arm rests, with one knee bent with the ipsilateral foot totally bound to the ground, while the other leg was extended and with the heel leaning on the floor and ankle flexed at approximately $90^{\circ}$. At the examiner's command, the subject took both hands superposed towards the extended foot, without flexing the knee. In this test, a $45 \mathrm{~cm}$ ruler was used to measure the distance from the foot to the hand. The test was performed three times, being the best result computed.

\section{Back reach}

The subject started standing and at the examiner's command placed one hand over the scapular girdle, behind the neck towards the back, as low as possible, and the with the other hand tried to meet the contralateral fingers from below. In this test, a $45 \mathrm{~cm}$ ruler was used to measure the distance from the foot to the hand. 
The test was performed three times, being the best result computed.

\section{Time Up and Go}

The subject started sitting in a chair without arm rests, without leaning its back on the chair, hands rested on the thighs and feet bound to the ground. At the examiner's command, it was instructed to get up, walk a distance of $2.44 \mathrm{~m}$ and return to the chair, this time sitting with the back leaning against it. This process had to be done as fast as possible, without actual running. In this evaluation, a plastic cone was used to mark the distance, and a Vollo VL237 chronometer (São Paulo, Brazil) was used to track time. The test was performed three times, being the best result computed.

\section{2 minute Step test}

Beginning with the subject standing, the examiner marked the mean point of the subject's thigh (half distance between the kneecap apex and the iliac crest), using a metallic and flexible measuring tape of the Sanny brand (São Paulo, Brazil). Afterwards, this point was transferred to a Sanny stadiometer (São Paulo, Brazil), which was kept next to the subject throughout the evaluation. Starting from the standing position, at the examiner's command, the subject should march in place for two minutes. To be taken into account, the steps should be performed with the knee reaching at least the point determined by the stadiometer. Time was measured using a Vollo VL237 chronometer (São Paulo, Brazil).

The EG data were collected during the activity period in RALs, in the morning shift, while in the cohabitation houses the tests were performed in usable indoor locations. The testes were performed in the moments before and after intervention with an interval of three months between them.

\section{Statistical analysis}

The mean \pm standard deviation was used to characterize the variables in terms of central tendency and dispersion. To perform the inferential analysis, the normality and homogeneity were assessed with Shapiro-Wilk and Levene respectively. After parametric statistic was assured, a t-test for independent measures was used to detect possible differences in the initial values between groups. To assess possible disagreements among the analysis moments and between the different groups, an ANOVA for repeated measures with the 2 models $x 2$ groups model was used. When a variable registered significant changes in the initial values, an ANCOVA was used between groups, with the initial values as covariables. The partial eta squared was used to estimate the second effect (Cohen, 1998). The adopted significance level was $5 \%$.

\section{RESULTS}

The To the anthropometric variables the ANOVA indicated a significant moment effect for the stature $\left(\mathrm{F}_{(1.38)}=7.815 ; \mathrm{p}=0.008 ; \eta_{\mathrm{p}}{ }^{2}=0.171\right)$ and BMI $\left(\mathrm{F}_{(1.38)}=4.204 ; \mathrm{p}=0.047 ; \eta_{\mathrm{p}}{ }^{2}=0.100\right)$, a moment $\mathrm{x}$ group interaction for the age $\left(\mathrm{F}_{(1.38)}=4.877 ; \quad \mathrm{p}=0.033 ; \quad \eta_{\mathrm{p}}{ }^{2}=0.114\right)$, stature $\left(\mathrm{F}_{(1.38)}=13.471 ; \mathrm{p}=0.001 ; \eta_{\mathrm{p}}{ }^{2}=0.262\right)$ and BMI $\left(\mathrm{F}_{(1.38)}=12.156 ; \mathrm{p}=0.001 ; \eta_{\mathrm{p}}{ }^{2}=0.242\right)$ variables. No group effect was noted in these variables.

When each group is individually analyzed (see table 1), there is a significant increase in the BMI $\left(\mathrm{F}_{(1.22)}=17.501 ; \mathrm{p}<0.0001 ; \eta_{\mathrm{p}}{ }^{2}=0.443\right)$, stature, by contrast, was significantly reduced $\left(\mathrm{F}_{(1.22)}=24.513 ; \mathrm{p}<0.0001 ; \eta_{\mathrm{p}}{ }^{2}=0.527\right)$. In the $\mathrm{CG}$, only age appeared to increase significantly $\left(\mathrm{F}_{(1.22)}=81.920 ; \mathrm{p}<0.0001 ; \eta_{\mathrm{p}}{ }^{2}=0.837\right)$.

To the functional variables the ANOVA indicated a significant moment effect for the 2MST $\left(\mathrm{F}_{(1.38)}=5.505 ; \mathrm{p}=0.024 ; \eta_{\mathrm{p}}{ }^{2}=0.127\right)$ and in BR; $\left.\eta_{\mathrm{p}}{ }^{2}=0.296\right)$. A moment $\mathrm{x}$ group interaction was also perceived in the $\mathrm{EF} \quad\left(\mathrm{F}_{(1.38)}=9.692\right.$; $\left.p=0.004 ; \quad \eta_{p}{ }^{2}=0.203\right)$. None of the analyzed variables showed a group effect.

When observed individually, there was significant increase in $\mathrm{EF}$ in the $\mathrm{EG}\left(\mathrm{F}_{(1.22)}=7.876\right.$; $\left.\mathrm{p}=0.010 ; \eta_{\mathrm{p}}{ }^{2}=0.264\right)$. In the CG there was a significant increase in the $2 \mathrm{MST}\left(\mathrm{F}_{(1.22)}=13.200\right.$; $\mathrm{p}=0.002 ; \eta_{\mathrm{p}}{ }^{2}=0.452$ ). 
Table 1

Mean \pm Standard deviation of the age, stature, body mass and BMI variables pre and post intervention in control and experimental groups

\begin{tabular}{lcccccc}
\hline & \multicolumn{2}{c}{ EG } & & & CG & \\
& Pre & Post & P & Pre & Post & P \\
\hline Age (years) & $82.70 \pm 3.18$ & $83.17 \pm 3.76$ & $0.000^{*}$ & $82.57 \pm 3.78$ & $83.82 \pm 2.35$ & $0.000^{*}$ \\
ST (cm) & $151.48 \pm 5.47$ & $150.09 \pm 5.51$ & $0.000^{*}$ & $151.83 \pm 5.15$ & $151.24 \pm 5.89$ & 0.571 \\
BM $(\mathrm{kg})$ & $59.73 \pm 11.67$ & $61.91 \pm 13.99$ & 0.050 & $60.52 \pm 13.99$ & $58.24 \pm 6.98$ & 0.446 \\
BMI $\left(\mathrm{kg} / \mathrm{m}^{2}\right)$ & $26.06 \pm 5.05$ & $27.44 \pm 5.78$ & $0.000^{*}$ & $26.19 \pm 5.57$ & $22.55 \pm 3.62$ & 0.348 \\
\hline
\end{tabular}

Note. ST- stature; BM — body mass; BMI — body mass index; EG — experimental group; CG — control group; * $\mathrm{p}<0.05$ before and after intervention

Table 2

Mean \pm Standard deviation of the Rikli and Jones test results pre and post intervention in the experimental and control groups

\begin{tabular}{|c|c|c|c|c|c|c|}
\hline \multirow[b]{2}{*}{ TESTS } & \multicolumn{2}{|c|}{ EG } & \multicolumn{4}{|c|}{ CG } \\
\hline & Pre & Post & $\mathrm{p}$ & Pre & Post & $\mathrm{p}$ \\
\hline SS (times) & $11.87 \pm 2.43$ & $11.57 \pm 2.94$ & 0.543 & $10.76 \pm 2.14$ & $11.00 \pm 2.72$ & 0.727 \\
\hline EF (times) & $13.00 \pm 3.41$ & $15.09 \pm 3.60$ & $0.010^{*}$ & $14.65 \pm 3.90$ & $13.53 \pm 3.43$ & 0.103 \\
\hline 2MST (times) & $44.04 \pm 19.15$ & $47.70 \pm 26.18$ & 0.451 & $36.59 \pm 15.00$ & $47.24 \pm 10.96$ & $0.002 *$ \\
\hline SRT $(\mathrm{cm})$ & $0.57 \pm 14.92$ & $-1.84 \pm 10.31$ & 0.165 & $-3.62 \pm 7.74$ & $-1.68 \pm 10.61$ & 0.242 \\
\hline $\mathrm{BR}(\mathrm{cm})$ & $-10.74 \pm 10.14$ & $-8.84 \pm 9.89$ & 0.191 & $-2.36 \pm 12.99$ & $-4.59 \pm 9.91$ & 0.323 \\
\hline TUG (s) & $9.82 \pm 2.96$ & $10.93 \pm 4.13$ & 0.062 & $8.08 \pm 2.33$ & $7.73 \pm 2.30$ & 0.402 \\
\hline
\end{tabular}

Note. EG - experimental group; CG - control group; SS - seat and standing test; EF — Elbow flexion test; SRT — Seat and reach test; BR - Back reach; 2MST: 2 minute STEP; TUG: Time Up and Go; ${ }^{*} \mathrm{p}<0.05$ before and after intervention

\section{DISCUSSION}

The present study aimed to evaluate the effects of training program practiced in the RALRJ program on the functional autonomy of octogenarian elderly women, as it is a gradually declining variable occurring with aging, thus negatively impacting the elderly population wellbeing (Martinho et al., 2013; Rubbieri, 2013).

The sample presented was homogeneous regarding age and $\mathrm{BMI}$ in the CG and EG. It should be noted that the average BMI of both groups is in the normal range, staying below the obesity level (Pan-Americana Organization [OPAS], 2001). Changes in BMI reflect age related changes in body composition; nevertheless, the regular practice of physical activities throughout life may contribute to the maintenance of ideal patterns (OPAS, 2001; Kura, Ribeiro, Niquetti, \& Tourinho Filho, 2004; Koochek, Johansson, Kocturk, Sundquist, \& Sundquist, 2008). Although the CG present the same changes, this may indicate that the training program in question could be contribute to the maintenance of corporal mass among the assessed subjects. High values of this index may imply when correlated with the risk of death due to cardiovascular disease and diabetes, an increased risk of premature death (Sugimoto et al., 2016; Kołtuniuk, \& Rosińczuk, 2016).

Comparing our results with the Rikli and Jones test scores, it is clear that the values of the functional strength test in the lower limbs (9 to 14) and upper limbs (10 a 16) of both groups are within the expected range for their age. The same is not true for the lower limb $(-2.0$ to +3.0$)$ and upper limb mobility ( -5.5 to +0.0$)$, TUG ( 8.7 to 5.7) and 2MST (60 to 91), whose values were below the appropriate levels for both groups. It was expected that the EG sample would have better results, closer to the adequate values for the age range, thus showing improved functional autonomy due to physical activity. This was demonstrated in several studies, including Zago and Gobbi (2003) and Borges and Moreira (2009), among others.

When analyzing the results before and after intervention in the EG, minor improvements in the upper limbs' functional strength and mobility tests are notes, while in the CG there is a slim improvement in the lower limbs' functional strength, 2MST and lower limb mobility tests.

A significant improvement across every test result was expected in the EG. However, some factors may have interfered in this result. Throughout data collection, which took eight 
months, there was no attendance control among the subjects, and frequency is fundamental to achieve results in a training program. According to American College of Sports Medicine (ACSM, 2009) and Brentano and Pinto (2001), to occur chronic effects due to the accumulation of the acute effects of training program, it is necessary to perform physical exercise regularly.

Another factor which could have influenced the present results is the fact that the available gym equipment present in the program's venues does not allow for load increment, which can limit the subject's progression, given that to promote new adaptive changes the training load should progressively increase in order to achieve gains (Carvalho et al., 2012).

Nevertheless, the results without significant difference between the tests of the EG are still relevant because they indicate maintenance of variables related to physical aptitude levels, such as strength, mobility, dynamic balance and agility. This result is important to outbalance the natural loss of physical aptitude secondary to morphological, functional and biochemical changes that affect the body with aging (Hao et al., 2015; Carvalho et al., 2012, ACSM, 2009) and directly impair functional autonomy and wellbeing (Martinho et al., 2013). Regarding octogenarian individuals, our results are even more significant, because the decay is greater with age (Hao et al., 2015), demonstrating that the practice of exercise in the RALs can be a good strategy in the public policies toward functional autonomy and quality of life in this population.

The American College of Sports Medicine (ACSM, 2009), as well as research form Gill et al. (2016) state that the more active a person is, the least physical limitations it will have. Furthermore, studies like that of Borges and Moreira (2009) affirm that sedentary individuals have inferior autonomy to perform daily activities, when compared to physically active individuals. This brings us to believe that without physical exercise interference there could have been a greater decline in the results.

Despite this scenario, the CG behaved very similarly to the EG. To that extent, it is plausible to assume that the activities performed in the cohabitation houses, as well as any other extra activities, had a positive impact in the CG. The lack of control of such activities as well as the attendance control among subjects of EG configures a limitation in this study.

\section{CONCLUSION}

The presented results allow us to conclude that the training program developed in Rio de Janeiro's RALs only promote the functional strength of the upper limbs and maintain the functional autonomy of octogenarian elders women's.

In face of the limitations exposed in the present research, it is suggested that more studies are developed to confirm if the methodology utilized by the program, as well as the use of equipment without load control, are really efficient in the physical training of the elderly women.

\section{Acknowledgments:}

Nothing to declare.

\section{Conflict of interests:}

Nothing to declare.

\section{Funding:}

Nothing to declare.

\section{REFERENCES}

American College of Sports Medicine (ACSM). (2009). Position Stand. Exercise and phisycal activity for older adults. Med Sci Sports Exerc, 41(7), 15101530. doi: 10.1249/MSS.0b013e3181a0c95c.

Appolinário, F. (2012). As dimensões da pesquisa. In F. Appolinário, Metodologia da ciência: filosofia e prática da pesquisa (2a ed. pp. 59-71). São Paulo, SP: Cengage Learning.

Bandeira, L. M., Melo, H. P, \& Pinheiro, L. S. (2010). Mulheres em dados: o que informa a Pnad/IBGE, 2008. In Brasil, Presidência da República, Secretaria de políticas para as mulheres (Eds). Observatório Brasil da Igualdade de Gênero ( $1^{\mathrm{a}}$ ed., pp 107- 119). Brasília, DF: Secretaria de Políticas Públicas para as Mulheres.

Borges, M. R. D., \& Moreira, A. K. (2009). The Influences of the physical activity practice on aging: A comparative study on the autonomy level for performance on DLAs and IADLs between the physically active and sedentary elderly. Motriz, 15(3), 562-573. 
Brentano, M. A., \& Pinto, R. S. (2001). Neural adaptations to strengthttraining. Revista Brasileira de Atividade Física e Saúde, 6(3), 65-77. doi: 10.12820/rbafs.v.6n3p65-77

Carvalho, T. B., Yamada, A. K., Crepaldi, M. D, Souza, J. C, Prestes, J., \& Verlengia, R. (2012). Eccentric resistance training in elderly: review on the acute and chronic physiological adaptations. Revista Brasileira de Ciências e Movimento, 20(4): 112-121.

Cohen, J. (1988). Statistical power analysis for the behavioral sciences ( $2^{\mathrm{a}}$ ed). New Jersey: Lawrence Erlbaum Associates.

Farinatti, P. T. V., Assis, B. F. C. B., \& Silva, N. S. L. (2008). Autonomy of action among elderly women on physical activity programs in Brazil and Belgium: a comparative study. Revista Brasileira de Cineantropometria e Desempenho Humano, 10(2), 107-114.

Gill, T. M., Pahor, M., Guralnik, J. M., Mcdermott, M. M., King, A. C., Buford, T. W., ... Miller, M. E. (2016). Life Study Investigators. Effect of structured physical activity on prevention of serious fall injuries in adults aged 70-89: randomized clinical trial (LIFE Study). British Medical Journal, 352, i245. doi: 10.1136/bmj.i245.

Gordon, C., Chunlea, W. C, \& Roche, A. F. (1988). Stature, recumbent length, and weight. Champaign: Human Kinetics.

Hao, Q., Yang, M., Luo, L., Hai, S., Ding, X., \& Dong, B. (2015). The association of falls and various physical activities in Chinese nonagenarians/centenarians. Archives of Gerontology and Geriatrics, 61(1), 21-26. doi: 10.1016/j.archger.2015.04.008.

Jankovic, N., Geelen, A., Streppel, M. T, Groot, L. C. P. G. M., Jong, J. C. K., Orfanos P., ... Feskens, E. J. (2015). WHO guidelines for a healthy diet and mortality from cardiovascular disease in European and american elderly: the chances project. American Journal of Clinical Nutrition, 102(4), 745-756. doi: 10.3945/ajcn.114.095117

Kołtuniuk, A., \& Rosińczuk, J. (2016). The prevalence of risk factors for cardiovascular diseases among Polish surgical patients over 65 years. Clinical Interventions in Aging, 13(11), 631-639. doi: 10.2147/CIA.S105201.

Koochek, A., Johansson, S. E., Kocturk, T. O., Sundquist, J., \& Sundquist, K. (2008). Physical activity and body mass index in elderly Iranians in Sweden: a population-based study. European Journal of Clinical Nutrition, 62(11), 1326-1332. doi: 10.1038/sj.ejen.1602851

Küchemann, B. A. (2012) Envelhecimento populacional, cuidado e cidadania: velhos dilemas e novos desafios. Sociedade e Estado, 27(1): $\quad 165-180$. doi: 10.1590/S010269922012000100010.

Kura, G. G., Ribeiro, L. S. P., Niquetti, R., \& Tourinho Filho H. (2004). Physical activity level, ICM and indexes of static muscular strength between hydro gymnastic and elderly gymnastic practitioner. Revista Brasileira de Ciência $e$
Envelhecimento Humano, 1(2), 30-40. doi: 10.5335/rbceh.2012.12.

Martin, A. D., Carter, J. E. L., Hendy, K. C., \& Malina, R. M. (1988). Segment lengths. Champaign: Human Kinetics.

Martinho, K. O, Dantas, E. H, Longo, G. Z, Ribeiro, A. Q, Pereira, E. T, Franco, F. S, ... Tinôco, A. L. (2013). Comparison of functional autonomy with associated sociodemographic factors, lifestyle, chronic diseases (CD) and neuropsychiatric factors in elderly patients with or without the metabolic syndrome (MS). Archives of Gerontology and Geriatrics, 57(2), 151-155. doi: 10.1016/j.archger.2013.04.005.

Ministério da Saúde. (2006). Portaria no 2.528 de 19 de outubro de 2006. Aprova a Política Nacional de Saúde da Pessoa Idosa. Acessado em: 01/06/2018. Disponível em: http://bvsms.saude.gov.br/bvs/saudelegis/gm/2 006/prt2528_19_10_2006.html

Ministério da Saúde. (2012). Resolução n 466, de 12 de dezembro de 2012. Aprova normas regulamentadoras de Pesquisas envolvendo seres humanos. Acessado em: 01/06/2018. Disponível em: http://bvsms.saude.gov.br/bvs/saudelegis/cns/ 2013/res0466 $12 \quad 12$ 2012.html.

Organização Pan-Americaña (OPAS). (2001). XXXVI Reunión del Comité Asesor de Investigaciones em Salud - Encuestra Multicêntrica - Salud Bienestar y Envejecimiento (SABE) en América Latina e el Caribe - Informe preliminar. Acessado em: 10/03/2002. Disponível em: http://www.opas.org/program/sabe.htm.

Ribeiro, G. S. Problemas de saúde da população brasileira e seus determinantes. (2014). In J. S. Paim \& N. Almeida-Filho (Eds), Saúde Coletiva: Teoria e Prática. (1 ${ }^{\mathrm{a}}$ ed. pp. 97-119) Rio de Janeiro, RJ: Medbook.

Rikli, E. R. \& Jones, C. J. (1999). Development and Validation of a Functional fitness test for Community Residing Older Adults. Journal of Aging and Physical Activity, 7(2), 129-161.

Rikli, E. R., \& Jones, C. J. (2002). Measuring functional fitness of older adults. Journal of Aging and Physical Activity, 24-30.

Rubbieri, G. (2013). Comorbidity, disability, frailty. Giornale Italiano Di Cardiologia, 14(3 Suppl 1): 611. doi: 10.1714/1261.13933.

Secretaria Especial de Envelhecimento Saudável e Qualidade de Vida - SESQV. (2010) Rio ao Ar Livre. Acessado em: 08/12/2015. Disponível em: <http://www.rio.rj.gov.br/web/sesqv/exibecont eudo?id $=126401>$.

Silva, N. L., Brasil, C., Furtado, H., Costa, J., Farinatti, P. (2014). Exercise and aging: health benefits and characteristics of the intervention programs at LABSAU/IEFD/UERJ. Revista HUPE, 13(2), 7585. doi: 10.12957/rhupe.2014.10129.

Sugimoto, T., Tsutsumimoto, K., Nakakubo, S., Murata, S., Doi, T., \& Ono, R. (2016). Abdominal obesity mediates the association between a low physical activity and a decline in gait speed in 
community-dwelling elderly people: A crosssectional study. Japanese Journal of Geriatric, 53(1), 54-61. doi: 10.3143/geriatrics.53.54.

Thomas, J. R., Nelson, J. K., \& Silverman, S. J. (2012). Métodos de pesquisa em atividade física ( $6^{\mathrm{a}}$ ed.). Porto Alegre, RS: Artmed.

World Health Organization (WHO). (2015). World report on ageing and health. Acessado em:
01/06/2018. Disponível em: http://www.who.int/ageing/publications/world -report-2015/en/.

Zago, A. S., \& Gobbi, S. (2003). Normative values of functional fitness in 60-to-70 year-old women. Revista Brasileira de Ciência e Movimento, 11(2), 7786.

All content of Journal Motricidade is licensed under Creative Commons, except when otherwise specified and in content retrieved from other bibliographic sources. 